\title{
A organização e disponibilização do Fundo Ernani Silva Bruno (ESB)
}

Vanderli Custódio ${ }^{1}$

\section{Introdução}

Com o incremento da área temática de Geografia no IEB, a partir do ano 2003, principiou o contato sistemático com as ricas fontes primárias existentes nos fundos e nas coleções mantidos sob a custódia do Instituto.

Com o objetivo de proceder à paulatina divulgação do acervo inédito da Unidade, assim como promover a aproximação dos formandos de Geografia e dar a conhecer a importância e as possibilidades de pesquisas de cunho geográfico diverso, no Setor do Arquivo ${ }^{2}$ do Instituto elaborou-se um projeto de organização ${ }^{3}$ do fundo pessoal do jornalista e historiador Ernani Silva Bruno (1912-1986), doado ao IEB em $1990^{4}$.

A escolha pelo Fundo pautou-se pelo interesse geográfico e multidisciplinar das temáticas trabalhadas pelo seu titular, bem como pela necessidade de listagem e divulgação dos documentos que o integram.

1 Professora doutora do Instituto de Estudos Brasileiros. Área temática de Geografia. E-mail: vanderli@usp.br

2 Arquivos em geral. O historiador francês Henri Hauser, a trabalho no Brasil nos anos 1940, preocupou-se em ressaltar o quanto os arquivos poderiam ser interessantes aos geógrafos e, após mencionar a Biblioteca Nacional, o Departamento de Cultura, a Câmara Municipal e órgãos congêneres da cidade do Rio de Janeiro, registrou: "[...] quis simplesmente orientar os geógrafos num caminho onde, creio, conseguirão resultados preciosos”. HAUSER, Henri. Algumas fontes da Geografia do Brasil. Boletim da Associação dos Geógrafos Brasileiro. São Paulo, ano III, n. 3, nov. 1943. p. 7 .

3 Com recursos da Codage da Reitoria da USP, foram selecionados seis estagiários: Camila Orsi Trevisan, José Augusto da Silva Pinto Júnior e Renata Alves Sampaio, na primeira fase (2005-2007), e Fernando Diório Alves dos Santos, Renata Moura Bacelar de Macedo e Rafael Cesário Aragi, na segunda fase (2008-2009).

4. No início de novembro de 2005 , a viúva de Ernani, a Sra. Maria Bartella (Dona Tutu), doou nova remessa de documentos ao IEB. 


\section{Biografia de Ernani Silva Bruno (ESB)}

Portador de simplicidade, repulsivo a formalidades, conversador cativante, extremamente generoso, bom ouvinte, despojado nos escritos e na fala, "rigoroso nas observações, contido e discreto nas poucas e profundas afirmações sobre a realidade que o cercava" e possuidor de agudo senso crítico, são alguns dos adjetivos utilizados por Murilo Marx ${ }^{5}$ para referir-se a Ernani Silva Bruno, nascido em 10 de agosto de 1912, na cidade de Curitiba, no Paraná.

Em 1925, mudou-se para São Paulo, onde cursou o colégio Liceu do Rio Branco e, em 1934, formou-se bacharel em Direito pela Faculdade do Largo de São Francisco - carreira que nunca chegou a exercer, cursando-a apenas para atender a um desejo do pai.

Por volta de 1932, iniciou as atividades jornalísticas no periódico A Noite e, entre 1935 e 1936, escreveu nos jornais Ação e Defensiva, ambos ligados ao Movimento Integralista ${ }^{6}$, fechados em 1937 pelo regime do Estado Novo.

Nas décadas subsequentes, Ernani escreveu em diversos periódicos, como Jornal da Manhã (1937-1945), jornais A Noite, A Noitinha (1943), jornal O Estado de S. Paulo (1943-1953), Diário de São Paulo (1955-1961), revista Coopercotia (1964-1967), jornal O Repórter (1966), revista Cruzeiro (1972) e jornal Folha de S. Paulo (1979-1986).

Em 1946, ingressou na carreira pública, com a nomeação para redator da Diretoria Estadual de Imprensa e Propaganda. Trabalhou na Comissão do IV Centenário da Cidade de São Paulo (1953), encarregada das festividades pelos quatrocentos anos da cidade; na Comissão do Parque do Ibirapuera (1957); no Museu da Casa Brasileira (1970$1979)^{7}$, do qual foi o primeiro diretor; e no Museu da Imagem e do Som (1980-1985).

5 MARX, Murilo. Ernani Silva Bruno. Grandeza do perfil. Revista do Instituto de Estudos Brasileiros, São Paulo, n. 27, 1987. p. 137-139.

6 Ernani teria sido convidado a participar de uma reunião com um grupo de estudantes reunido na casa de Plínio Salgado, todos interessados na fundação de uma sociedade de estudos políticos sobre o Brasil, da qual a Ação Integralista Brasileira seria somente um apêndice. Entretanto, o apêndice tornou-se o setor principal, no qual Ernani foi progressivamente ficando "[...] decepcionado ao sentir que ao invés de em uma aventura intelectual acabara envolvido em uma aventura política [...]". BRUNO, Ernani S. Almanaque de memórias: reminiscências - depoimentos e reflexões. São Paulo: Hucitec/Instituto Nacional do Livro/ Fundação Nacional Pró-Memória, 1986. p. 112.

7 O referido Museu disponibilizou em seu site um conjunto de 28 mil fichas sobre os equipamentos, usos e costumes da casa brasileira, entre os séculos XVI e XIX, elaboradas por Ernani quando foi diretor da entidade. 
Na sua literatura histórica ${ }^{8}$, três temas foram frequentes: o Brasil geral e regional, o estado de São Paulo e, principalmente, a cidade de São Paulo. Acerca deles publicou ou organizou diversas obras, dentre elas o clássico, em três volumes, História e tradições da cidade de São Paulo (1953); História e paisagens do Brasil ${ }^{9}$ (1958-59), com dez volumes, organizados por Diaulas Riedel, com introdução, seleção e notas de ESB; Imagem da formação do Brasil (1962); Viagem ao país dos paulistas (1966), São Paulo: terra e povo (1966); organizado por ESB; História do Brasil geral e regional (1967), com seis volumes; O equipamento da casa bandeirista, segundo os antigos inventários e testamentos (1977); Memória da cidade de São Paulo (1981); Catálogo de depoimentos do Museu da Imagem e do Som: 1970/1982 (1983); e as obras póstumas, Almanaque de memórias: reminiscências - depoimentos e reflexões (nov. de 1986) e Café \& negro ${ }^{10}$ (2005). Para tanto, utilizou as mais diversas fontes: documentação oficial, coleções de manuscritos, crônicas de viajantes, literatura de ficção, produção de memorialistas, iconografia ${ }^{11}$ (fotografia, cartões-postais), cartas, poesias, cardápios ${ }^{12}$, obras etnográficas e inúmeras outras fontes da cultura material.

No ano de 1984, tornou-se membro da Academia Paulista de Letras, onde faleceu durante uma reunião, em 25 de setembro de 1986.

\section{Sobre o fundo ESB}

O Fundo é composto por 33.294 documentos entre os gêneros textual (manuscritos, datiloscritos de ensaios, recortes de jornal, correspondência, anotações e fichário), iconográfico (cartões-postais,

8 LOFEGO, Sílvio Luiz. Memória de uma metrópole: São Paulo na obra de Ernani Silva Bruno. São Paulo: Annablume/ Fapesp, 2001. p. 18.

9 Volumes existentes na biblioteca do IEB: v. 2 - O sertão, o boi e a seca: Maranhão, Piauí, Ceará e Rio Grande do Norte; v. 3 - Os canaviais e os mocambos: Paraíba, Pernambuco e Alagoas; v. 4 - Coqueirais e chapadões: Sergipe, Bahia; v. 5 - A cidade, o mar e as serras: Espírito Santo, Rio de Janeiro e Distrito Federal; v. 7 Pinheirais e marinhas: Paraná e Santa Catarina; v. 8 - O pampa e os cavaleiros: Rio Grande do Sul; v. 9 - O ouro e a montanha: Minas Gerais; v. 10 - As selvas e o pantanal: Goiás e Mato Grosso.

10 O livro Café \& negro foi escrito em 1953, para integrar o Concurso de peças de teatro, cinema e monografia histórica, realizado pela Comissão do IV centenário do aniversário da cidade de São Paulo. Nenhum trabalho foi premiado. Ernani obteve recomendação para que a obra fosse publicada, mas não o fez.

11 MARX, Murilo. op. cit., p. 137-138.

12 LOFEGO, Sílvio Luiz. op. cit., p. 72. 
fotografias e gravuras) ${ }^{13}$ e audiovisual (fita cassete), além dos volumes da biblioteca ${ }^{14}$ (Tabela 1).

Tabela 1 - Documentos do Fundo ESB

\begin{tabular}{|c|c|}
\hline Documentos & Quantidades \\
\hline Textuais & $\mathbf{2 6 . 0 6 9}$ \\
\hline Fichário & 20.707 \\
\hline Outros & 5.355 \\
\hline Iconográficos & $\mathbf{4 . 3 2 9}$ \\
\hline Cartões-postais & 1.708 \\
\hline Fotografias (em papel, slides, \\
negativos flexíveis e em vidro) & 2.374 \\
\hline Outros & 247 \\
\hline Audiovisuais & $\mathbf{1}$ \\
\hline Fitas cassetes & 3 \\
\hline Biblioteca & $\mathbf{4 . 0 0 0}$ \\
\hline & $\mathbf{3 4 . 3 9 9}$ \\
\hline
\end{tabular}

Fonte: Área de Geografia do IEB-USP, mar. 2010.

O projeto deteve-se nos documentos textuais, dos quais cabe destacar a cobertura temporal dos recortes de jornais e a grandeza do fichário - são 20.707 unidades, distribuídas por dezenove subfichários ${ }^{15}$ (assuntos) demonstrativos do interesse do titular. (Tabela 2)

Tabela 2 - Conjunto do Fichário do Fundo ESB.

\begin{tabular}{|c|c|}
\hline Título dos subfichários & N. de fichas \\
\hline Autores & 1.911 \\
\hline Cidades brasileiras e países & 563 \\
\hline Estampas - Assuntos & 245 \\
\hline Estampas - Localidades & 565 \\
\hline Fichário da cidade de São Paulo & 1.706 \\
\hline
\end{tabular}

13 Com exceção da lista de gravuras, os demais documentos iconográficos estão arrolados no site do IEB.

14. De sua biblioteca constam autores como Carlos Drummond de Andrade e os geógrafos Aroldo de Azevedo, Jean Tricart, Pierre Monbeig, e quinze obras de sua autoria ou colaboração.

15 Estão reproduzidos e encadernados para facilitação de consulta, com exceção do "Fichário sem nome", o único sem elaboração de fichas-guia por parte de Ernani. 


\begin{tabular}{|c|c|}
\hline Fichário sem nome & 2.390 \\
\hline Glossário de atividades e tipos regionais & 150 \\
\hline Gravuras da cidade de São Paulo & 2.001 \\
\hline Índice bibliográfico temático A & 3.278 \\
\hline Índice bibliográfico temático B & 1.653 \\
\hline Índice de nomes de ruas antigas da cidade de São Paulo & 935 \\
\hline Inventários e testamentos & 3.289 \\
\hline Mundo caipira & 570 \\
\hline Origem das cidades paulistas & 30 \\
\hline Personalidades & 35 \\
\hline Região Sudeste & 496 \\
\hline Regiões brasileiras sem o Sudeste & 421 \\
\hline Topônimos - continentes & 175 \\
\hline Total & 294 \\
\hline
\end{tabular}

Fonte: Área de Geografia do IEB-USP, mar. 2010.

\section{Uma proposição metodológica}

A produção de instrumentos de pesquisa no Fundo ESB exigiu o enveredamento pelos caminhos da disciplina de Arquivística, ausente dos currículos dos egressos dos cursos de Geografia, sejam eles pesquisadores ou técnicos. O objetivo da Arquivística, segundo Camargo e Belloto, é "[...] o conhecimento da natureza dos arquivos e das teorias, métodos e técnicas a serem observados na sua constituição, organização, desenvolvimento e utilização" ${ }^{\prime 16}$.

O contato com a disciplina postou o desafio de como proceder à organização $0^{17}$ - descrição e classificação - dos documentos de Ernani,

16 Belloto, Heloísa L.; CAMARgO, Ana Maria de A. Dicionário de terminologia arquivística. São Paulo: Associação dos Arquivistas Brasileiros/Núcleo Regional São Paulo: Secretaria de Estado da Cultura, 1996. p. 5 .

17 "A organização arquivística de qualquer acervo pressupõe não apenas as atividades de classificação, mas também as de descrição. Somente a descrição arquivística garante a compreensão ampla do conteúdo de um acervo, possibilitando tanto o conhecimento quanto a localização dos documentos que o integram. Nesse sentido, podemos afirmar que as atividades de classificação só conseguem ter seus objetivos plenamente atingidos mediante a descrição documental”. LOPES, André P. A. Como descrever documentos de arquivo: elaboração de instrumentos de pesquisa. São Paulo: Arquivo do Estado/ Imprensa Oficial do Estado, 2002. p. 15 . 
preservando os pilares da teoria arquivística ${ }^{18}$, constituídos pelos princípios da proveniência, da organicidade, da unidade, da indivisibilidade e da cumulatividade, e, ao mesmo tempo, criar um modelo de instrumento de busca que significasse um passo adiante no caminho da disponibilização do acervo do Instituto.

A trajetória organizativa, constituída por avanços e retrocessos, no sentido de tornar viável a construção de tal instrumento, teve por premissa a defesa da extroversão de dados, informações e conhecimentos existentes e produzidos em instituições públicas do país a interessados em geral. Trata-se de uma finalidade social; portanto, buscou-se um meio-termo entre o tempo lento da extroversão de um fundo, resultante de pesquisa minuciosa, e o tempo urgente da pesquisa pelos consulentes. No caso do Fundo ESB, quantas décadas e pesquisadores seriam demandados para tornar públicos os milhares de documentos que o compõem, num tempo lento de investigação?

Desta feita, chegou-se à seguinte metodologia: descrição simples de cada documento, conhecimento da vida e obra do signatário do fundo, classificação com a construção de uma cronologia estratificada e, a partir dela, a elaboração de um banco de dados. No caso, enquanto uma equipe trabalhava com os documentos textuais, outra se preocupava com os iconográficos ${ }^{19}$, visto serem distintos os suportes de cada gênero documental. O diálogo constante entre as duas equipes salvaguardou o princípio da organicidade do fundo.

\section{Fase inicial: Acondicionamento e higienização básica}

Quando do início dos trabalhos, o Fundo ESB encontrava-se acondicionado em caixas de papelão amarelo, com etiquetação provisória. Na higienização básica procedeu-se à retirada dos clipes e grampos metálicos dos documentos, escovação frente e verso e retirada de pó. Para o reacondicionamento, foram substituídos os clipes e grampos de metal por similares de plástico, cada documento foi envolvido numa capa de papel filiset neutro e, na sequência, restituído à caixa de origem.

18 BELloto, Heloísa L. Arquivística: objetos, princípios e rumos. São Paulo: Associação de Arquivistas de São Paulo, 2002. p. 20-21.

19 Embora o projeto tenha eventualmente auxiliado na listagem dos documentos iconográficos, especificamente dos cartões-postais (1.708), eles foram alvo de projeto distinto, levado a efeito pela arquivista Maria Helena Pinoti (Serviço de Arquivo do IEB) e pelos estagiários Bruno dos Santos Silva, Lílian Cristina M. Vieira da Cruz, Luana Cristina Biondo, Luis Gustavo B. Caldeira, Melina Rodolpho e Olívia Brenga Marques. 


\section{Descrição simples e etiquetação de caixas}

Sob orientação dos técnicos do Arquivo $^{20}$, atentou-se para os itens que pudessem auxiliar o futuro consulente na localização das informações. Assim, atribuiu-se um número a cada documento, agrupando aqueles de natureza semelhante numa mesma pasta, e foi dado início à descrição simples de cada unidade, registrando no programa Microsoft Word as seguintes informações: "tipo de documento", "fonte", "título", "autoria", "data" e "número de páginas". Obteve-se, assim, uma listagem em três vias: a primeira, guardada dentro da caixa descrita; a segunda, incorporada à listagem geral; e a terceira, disponibilizada no Arquivo, para uso inicial dos consulentes.

Com vistas à etapa de classificação documental, principiou-se a leitura de obras que pudessem oferecer noções de Arquivística ${ }^{21}$ e do livro autobiográfico de ESB, Almanaque de memórias (1986). As noções adquiridas possibilitaram, inclusive, maior controle do processo de descrição, por meio da elaboração de uma etiqueta, ainda provisória, para cada caixa.

\section{Cronologia estratificada preliminar}

Diante da indispensabilidade de se elaborar critérios a serem adotados para a classificação dos documentos do Fundo ESB, iniciou-se o preparo de uma cronologia estratificada. Neste sentido, houve avanço nos estudos de complementação da biografia do titular do fundo, com a construção de uma cronologia em lista o mais completa possível. Concomitantemente, elaborou-se um levantamento minucioso dos assuntos arrolados por Ernani em todas as fichas-guia dos subfichários.

A biografia, associada aos assuntos ${ }^{22}$ das fichas, possibilitou o estabelecimento de grupos e subgrupos caracterizadores da vida e obra do autor. Foram eles: "identidade civil", "relações familiares e sociais", "formação", "carreira pública", "estudos para obras", "jornalismo", "geografia e história", "política" e "universo de interesses".

20 Maria Izilda C. do Nascimento Fonseca Leitão, Maria Cecília F. de Castro Cardoso, Maria Helena Pinote, Mônica Aparecida Guilherme da Silva e Elisabete Marin Ribas. A todas agradeço pelas sugestões.

21 Sobretudo BELlOTO, Heloísa L.; CAMARGO, Ana Maria de A. Dicionário de terminologia arquivistica. op. cit.; e BELLOTO, Heloísa L. Arquivistica, op. cit.

22 Mais de 270 assuntos. 


\section{Resultados da fase inicial}

A descrição simples dos documentos textuais do Fundo ESB, num total de 63 caixas, resultou em correspondente inventário, constituído por três listagens ${ }^{23}$, colocadas à disposição dos consulentes no Arquivo. Considerou-se o inventário como uma primeira versão do conjunto documental do Fundo ESB.

Como resultados, além da citada cronologia estratificada preliminar, também foram determinadas as datas-limite da produção (1932-1986); a descoberta de potenciais temas de pesquisas geográficas $^{24}$, tais como Geografia política e geopolítica - formação do território brasileiro, ideologias geográficas (o pensamento integralista); Geografia retrospectiva - origem, evolução e problemas urbanos de várias cidades do estado de São Paulo; Geografia urbana - origem e formação de cidades paulistas e brasileiras, equipamentos, serviços, planejamento urbano, conservação do patrimônio histórico e cultural (edifícios, monumentos e ruas); Geografia agrária - brasileira e paulista, com destaque para a produção cafeeira e o mundo caipira, seus hábitos, usos e costumes; Geografia da população - imigração nacional e estrangeira para o Brasil e para o Estado de São Paulo, entre outras possibilidades.

Outro resultado foi a transcrição de entrevista concedida por ESB à pesquisadora Maria de Lourdes Julião ${ }^{25}$, em 1984, por ocasião da reedição, após trinta anos, do clássico História e tradições da cidade de São Paulo. Outro ainda, o mais importante, foi a identificação da metodologia de trabalho empregada por ESB ao longo da vida, qual seja: pesquisa textual e iconográfica em fontes primárias e secundárias existentes em arquivos e bibliotecas > apontamentos manuscritos em fichas > redação datiloscrita de artigos de jornal a partir dos levantamentos efetuados > autoria ou organização de livros com uso dos artigos de jornal e das fichas.

23 A primeira com 180 páginas (caixas 1 a 28), a segunda com 230 (caixas 29 a 51) e a terceira com 56 (caixas 52 a 63), num total de 466 páginas.

24. Outros resultados foram uma iniciação científica com base no Fundo ESB (com bolsa $\mathrm{CNPq}$ ) e a apresentação e publicação de trabalho no XIV Encontro Nacional de Geógrafos, realizado em Rio Branco, em 2006.

25 Historiadora e pesquisadora que trabalhou com Ernani Silva Bruno no Museu da Casa Brasileira e no Museu da Imagem e do Som, nas décadas de 1970 e 1980, e que, voluntariamente, auxilia o Arquivo do IEB na organização do fichário do jornalista. 


\section{Fase final - Higienização básica, descrição simples \\ e acondicionamento}

No ano de 2005, a família de ESB enviou ao Instituto nova remessa de documentos, contendo principalmente gênero textual, como manuscritos, recortes de jornal, diplomas, correspondência ativa e passiva, encartes do Museu da Casa Brasileira e do Museu da Imagem e do Som, inúmeras fichas e alguns livros. Depois de higienizados, descritos e acondicionados, resultaram em 18 caixas, totalizando 81 caixas de documentos em todo o Fundo ESB.

\section{Revisão, complementação e finalização da cronologia estratificada}

Com a revisão das informações da biografia de ESB, foram corrigidas as imprecisões, foi complementada a lista de eventos e concluída a cronologia estratificada com grupos e subgrupos definitivos: "identidade civil", "relações sociais", "formação", "coleta e sistematização de dados", "atividade profissional: carreira pública e jornalismo", "atividade de pesquisa: história e geografia, literatura", "universo de interesses: política, arte e cultura".

A chegada da segunda remessa de documentos inspirou a seleção de imagens ${ }^{26}$ de documentos e livros que pudessem ter a função de link e, assim, ilustrar os eventos da cronologia. Mais de quatro dezenas de imagens foram selecionadas, digitalizadas e vinculadas à cronologia completa $^{27}$ (Anexo A), que se tornou mais um instrumento de pesquisa.

\section{Glossário, lista de assuntos e registro}

Com vistas ao registro da classificação do material do Fundo ESB, realizou-se o levantamento de todos os tipos documentais que o integram e, com apoio em literatura especializada ${ }^{28}$, organizou-se um

26 Parte desta etapa foi o levantamento dos referidos cartões-postais do Fundo ESB.

27 O objetivo era a disponibilização da cronologia completa, com link para imagens selecionadas, no site do IEB, o que foi impossibilitado por motivos de desajuste técnico na transposição de um resultado da Arquivística para a mídia digital.

28 CAMARgO, Ana Maria de; GOULART, Silvana. Tempo e circunstância: a abordagem contextual dos arquivos pessoais. São Paulo: Instituto Fernando Henrique Cardoso, 2007; CARDOSO, Maria Cecília F. de C.; MENEZES, Irani Dias de; MAIA, Ivani; 
glossário para uso do fundo. Também se procedeu ao refinamento da lista de assuntos das fichas-guia de pesquisa, resultando em 59 itens $^{29}$, uma espécie de vocabulário controlado.

\section{Catalogação dos documentos}

Para tal etapa, de relevância foi a reunião com professoras especialistas $^{30}$ e com o pessoal do Setor de Processamento de Imagem e Reprografia do $\mathrm{IEB}^{31}$ no sentido de definir uma ficha catalográfica eletrônica padrão para cada tipo de documento. Intentava-se uma versão aprimorada, a segunda do inventário, que permitisse a contextualização de cada documento no quadro da cronologia estratificada da vida e obra de ESB. Na ficha padrão constaram os seguintes itens: "registro" (impresso, fotocopiado, manuscrito ou datiloscrito), "documento" (espécies documentais, segundo o glossário específico), "notação" (código numérico do Fundo ESB, o número da caixa, da pasta e do documento), "grupo e subgrupo", "título", "autor", "local e data", "paginação", "assuntos e subassuntos" (com o estabelecimento de três assuntos principais, cada qual com os subassuntos correspondentes), e os campos optativos "recorte", "periódico" e "informações adicionais". Neste último campo, registraram-se, por exemplo, autoria de ilustrações, edições comemorativas, personalidades mencionadas etc.

Em um processo de "recorta e cola" do inventário para as fichas, obedeceu-se às peculiaridades de cada documento, resultando em um catálogo em três volumes, compreendido pelas 81 caixas $^{32}$ do Fundo ESB.

PEREIR A, Nivaldo. Glossário de espécies/formatos e tipos documentais da Universidade de São Paulo. Portaria GR No ${ }^{\circ}$ o8z/97 Anexo III. São Paulo: SAUSP - Sistema de Arquivos USP, out. 1997; Instituto de Estudos Brasileiros. Arquivo IEB. Glossário de termos e espécies documentais. São Paulo, 1996.

29 Cada qual com os subassuntos correspondentes, auxiliando na compreensão da diversidade de material produzido por Ernani.

30 Credita-se às professoras doutoras Johanna Wilhelmina Smit (Biblioteconomia-USP) e Ana Maria de Camargo (História-USP) todos os méritos da proposta e a nós as imperfeições, pela compreensão enviesada das orientações recebidas e da bibliografia consultada, a obra Como elaborar vocabulário controlado para aplicação em arquivos. SMIT, Johanna W.; KOBASHI, Nair Y. São Paulo: Arquivo do Estado e Imprensa Oficial do Estado, 200z. (Projeto Como Fazer, n. 10). Especialmente com Denis Machado Rossi.

32 Houve uma redistribuição dos documentos das caixas $71 \mathrm{e} 75$, resultando em caixas $71 \mathrm{~A}$ e $72 \mathrm{~B}$, bem como em caixas $75^{\mathrm{A}}$ e $75^{\mathrm{B}}$; assim, a numeração manteve-se em 81 , mas a quantidade de caixas passou para 83 . 


\section{Primeira proposta de um banco de dados digital}

Em trabalho conjunto com o Setor de Imagem e Reprografia do Instituto, elaborou-se um banco de dados preliminar com as informações básicas das fichas catalográficas (Quadro 1) e disponibilizou-se no site do IEB uma lista com 3.724 documentos do Fundo Ernani Silva Bruno, em dezembro de 2009.

\section{Quadro 1 - Exemplo de ficha completa de documento do Fundo}

\section{ESB no site do IEB}

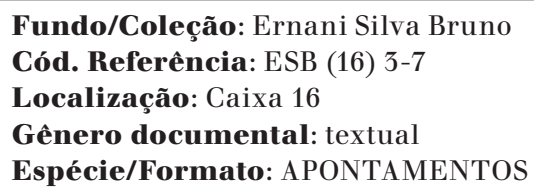

Fundo/Coleção: Ernani Silva Bruno

Cód. Referência: ESB (16) 3-7

Localização: Caixa 16

Gênero documental: textual

Espécie/Formato: APONTAMENTOS

Título: Capítulos de exploração humana no Brasil

Descrição: Manuscrito. Envelope pardo: "Literatura de Viajantes, Roteiros, Anotações Folclóricas e Humanísticas"

Localidade: São Paulo (SP)

Idioma: Português

No. de Páginas: 1

Autor: BRUNO, Ernani Silva

Disponível em: < http://www.ieb.usp.br >. Acesso em: 10 mar. 2010.

\section{Segunda proposta de um banco de dados digital}

Quando parte da organização do fundo estava concluída, o Setor de Processamento de Imagem e Reprografia do Instituto e um especialista em engenharia da computação ${ }^{33}$ propuseram uma planilha eletrônica simples, porém potencialmente alimentadora de diversos tipos de bancos de dados de fundos pessoais, como o de Ernani Silva Bruno. Assim, efetuou-se a conversão automática das informações de um banco a outro, bem como sua complementação. Tratou-se de uma terceira versão do registro dos documentos do Fundo, traduzido em um banco de dados mais completo, incorporador das informações obtidas na cronologia estratificada.

O novo modelo permite o desenvolvimento de pesquisas temáticas e a impressão de relatórios baseados em interesses definidos de estudo.

33 Trata-se de Frederico Antônio Camillo Camargo, estagiário do curso de Letras, antes encarregado da construção de um banco de dados para o Fundo de Aracy de Carvalho Guimarães Rosa e, atualmente, organizador do Fundo Guimarães Rosa. 
É exequível, por intermédio do recurso "auto filtro", a seleção de documentos com o auxílio da lista de assuntos; por exemplo, se o interesse do pesquisador for imigrações italiana e japonesa no Estado de São Paulo, pode-se selecionar os assuntos "População, povo e povoamento", "Migrantes e migrações" e "Estado de São Paulo"; caso o interesse seja o ciclo minerador brasileiro, com ênfase na mão de obra utilizada, selecionar "Tipos brasileiros", "Escravos e escravidão" e "Práticas e produtos extrativistas", para a obtenção da lista de documentos pertinentes. Viável ainda é a seleção de documentos por intermédio dos grupos indicados na cronologia estratificada, como "atividade profissional" e "universo de interesses", ou por espécie: cartões-postais, fotos etc.

O banco, lembrando que o conjunto do fichário recebeu registro por agrupamento de fichas ${ }^{34}$, conta com 8.757 documentos classificados (Tabela 3).

Tabela 3 - Banco de dados do Fundo ESB por grupos

\begin{tabular}{|c|c|}
\hline Documentos & Quantidades \\
\hline Grupo relações sociais & 160 \\
\hline Grupo coleta e sistematização de dados & 2.457 \\
\hline Grupo atividade profissional & 2.008 \\
\hline Grupo atividade de pesquisa $\left(^{*}\right)$ & 1.013 \\
\hline Grupo universo de interesse & 142 \\
\hline Cartões-postais & 1.708 \\
\hline Fotografias & 2.374 \\
\hline Total & $\mathbf{9 . 8 6 2}$ \\
\hline
\end{tabular}

Fonte: Setor de Arquivo do IEB, mar. 2010.

(*) 425 registros correspondem às fichas-guia do conjunto do fichário.

\section{Etiquetação, transferência de caixas e resultado final}

O registro na planilha eletrônica foi acompanhado pela elaboração de novas etiquetas e transferência de todos os documentos do Fundo ESB para dezenas de novas caixas (polionda cinza).

34 Uma espécie de catálogo seletivo. Exemplo: do subfichário "Estampas - Assunto", registrou-se a ficha-guia Abastecimento de água, 10 páginas. Isso significa que no item registrado estão agrupadas 10 fichas. Ficha-guia Artes e Letras, 11 páginas; agrupamento de 11 fichas num único registro e assim sucessivamente. Por conta disso, o número de documentos do grupo "Atividade de pesquisa" (mais de 20.707) é muito maior do que o número de registros (1.013). 
Os principais resultados ${ }^{35}$ da proposta de organização foram, indubitavelmente, o banco de busca ${ }^{36}$ documental preliminar do Fundo ESB, disponível no site do IEB desde o ano de 2009, e o banco definitivo, disponibilizado em abril de 2010.

\section{Considerações finais}

Apesar dos erros, acertos, desacertos e recomeços, característicos do tatear do aprendiz (o formado em Geografia) em terreno desconhecido (a Arquivística), o processo de trabalho proporcionou a disponibilização objetivada, a aproximação de graduandos de Geografia com o IEB, por intermédio de estágios e iniciações à pesquisa, e um avanço significativo na extroversão dos fundos e das coleções custodiadas pelo Instituto.

35 Considerados resultados também são duas iniciações científicas pautadas na exploração documental do Fundo ESB, ambas com bolsa do CNPq; a apresentação e publicação de trabalho em coautoria com Fernando Diório no XV Encontro Nacional de Geógrafos, realizado em São Paulo, em 2008. Resultado e resultante foi o inestimável auxílio do CNPq na aquisição de computadores e papel filiset neutro.

$3^{6}$ Aos moldes do mesmo banco de busca, estão em fase de teste no Setor de arquivo do IEB documentos dos seguintes fundos: Anita Malfatti (1.o67 documentos), Aracy de Carvalho Guimarães Rosa (5.615 documentos), Caio Prado Jr. (1.938 documentos), Fernando de Azevedo (16.319 documentos), Fernandes Mendes de Almeida (12 documentos), Francisco Mignone (13 documentos), João Guimarães Rosa (7.219 documentos), José Honório Rodrigues (920 documentos), Lélia Abramo (36 documentos). 
ANEXO A

CRONOLOGIA ESTRATIFICADA DA VIDA E OBRA DE ERNANI SILVA BRUNO ${ }^{37}$

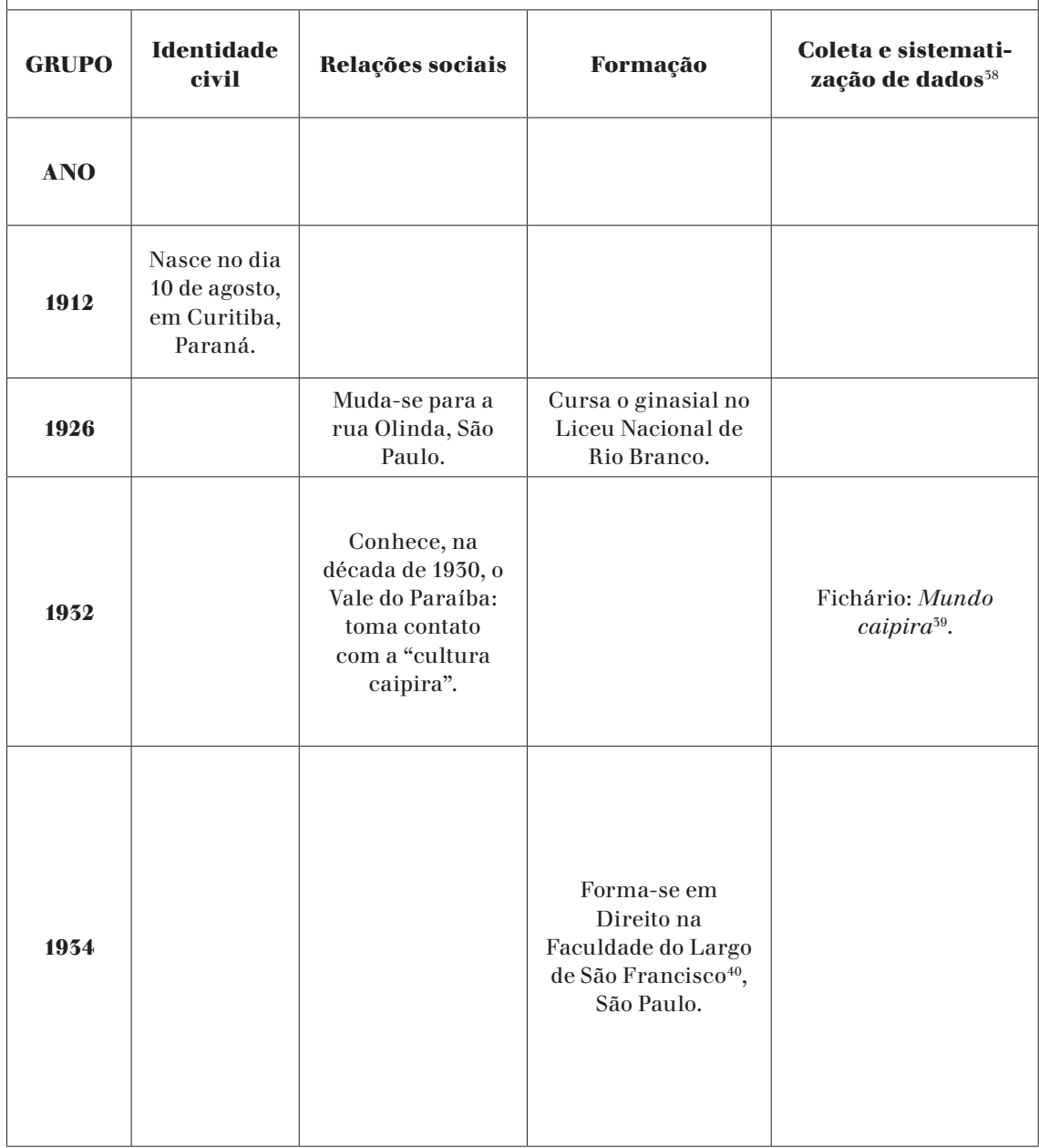

37 Cronologia incompleta, para efeito de demonstração. Organizada pelos estagiários do IEB - Área de Geografia: Fernando Diório Alves dos Santos e Renata Moura Bacelar de Macedo (2008).

38 A atividade de Coleta e sistematização de dados, materializada nos fichários e registros iconográficos, foi realizada ao longo de toda a vida profissional de Ernani Silva Bruno.

39 Ilustrativo, não compreende a totalidade dos assuntos e fichas produzidas.

40 As informações sobre o ano de ingresso de ESB na Faculdade de Direito são imprecisas. 


\begin{tabular}{|c|c|c|c|c|c|c|}
\hline \multicolumn{7}{|c|}{ CRONOLOGIA ESTRATIFICADA DA VIDA E OBRA DE ERNANI SILVA BRUNO ${ }^{37}$} \\
\hline GRUPO & \multicolumn{2}{|c|}{ Atividade profissional } & \multicolumn{2}{|c|}{ Atividade de pesquisa } & \multicolumn{2}{|c|}{$\begin{array}{l}\text { Universo de } \\
\text { interesses }\end{array}$} \\
\hline ANO & $\begin{array}{l}\text { Carreira } \\
\text { pública }\end{array}$ & Jornalismo & $\begin{array}{l}\text { História e } \\
\text { Geografia }\end{array}$ & Literatura & Política & $\begin{array}{l}\text { Arte e } \\
\text { cultura }\end{array}$ \\
\hline 1912 & & & & & & \\
\hline 1926 & & & & & & \\
\hline 1932 & & $\begin{array}{c}\text { Inicia a } \\
\text { carreira de } \\
\text { jornalista no } \\
\text { periódico } A \\
\text { Noite. }\end{array}$ & & & $\begin{array}{c}\text { Participa do } \\
\text { movimento } \\
\text { "Ação } \\
\text { Integralista } \\
\text { Brasileira": } \\
\text { Sociedade } \\
\text { de Estudos } \\
\text { Políticos, } \\
\text { 1932/1937. }\end{array}$ & \\
\hline 1934 & & $\begin{array}{c}\text { Escreve o } \\
\text { artigo “As } \\
\text { realidades } \\
\text { brasileiras } \\
\text { na concepção } \\
\text { integra- } \\
\text { lista", para o } \\
\text { periódico } O \\
\text { Nacionalista. }\end{array}$ & & & & \\
\hline & & & & & & \\
\hline
\end{tabular}




\section{Imagens da Documentação:}

\section{A organização e disponibilização do Fundo Ernani Silva Bruno (ESB)}
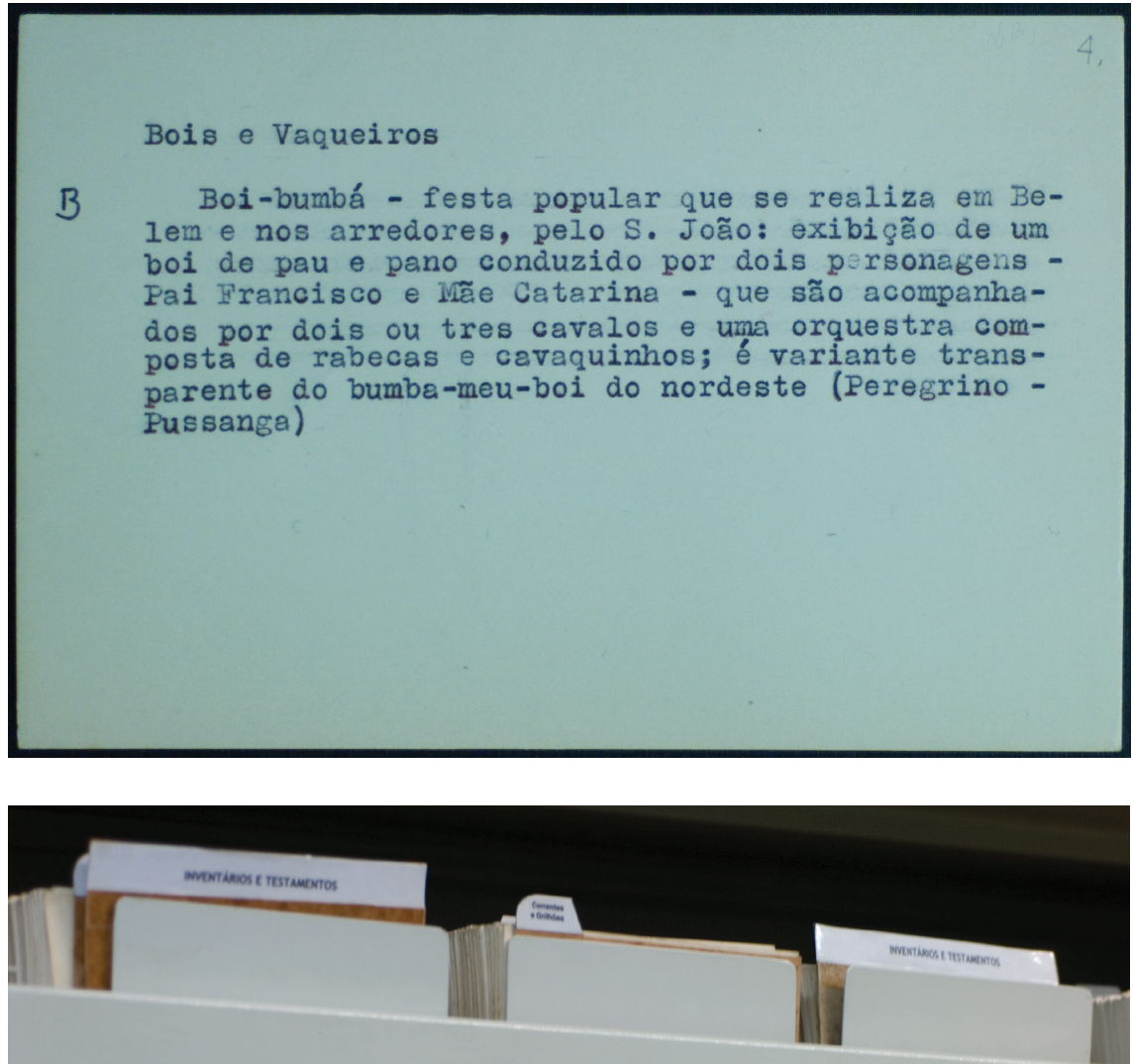

Figura 1. Ficha Bois e Vaqueiros. Setor do Arquivo do IEB-USP. Foto: Gabriela Lissa Sakajiri - Seção de Processamento de Imagem e Reprografia.

Figura 2. Fichário de ESB. Setor do Arquivo do IEB-USP. Foto: Ivanise Risério de Oliveira Seção de Processamento de Imagem e Reprografia. 